\title{
Frailty and quality of life in elderly patients with acute coronary syndrome
}

\author{
This article was published in the following Dove Press journal: \\ Clinical Interventions in Aging \\ 5 May 2016 \\ Number of times this article has been viewed
}

\author{
Magdalena Lisiak' \\ Izabella Uchmanowicz' \\ Radosław Wontor ${ }^{2}$ \\ 'Department of Clinical Nursing, \\ Wroclaw Medical University, \\ ${ }^{2}$ Department of Cardiology, \\ T. Marciniak Lower Silesian Specialist \\ Hospital, Wroclaw, Poland
}

\begin{abstract}
Background: Frail elderly people are at risk of developing adverse health outcomes such as disability, hospitalization, and mortality. In recent years, the literature has drawn attention to the role of frailty syndrome (FS) in acute coronary syndrome (ACS). There are few studies regarding the relationship between two multidimensional variables such as FS and quality of life (QoL). Objective: The aim of the study was to investigate the relationship between FS and early QoL of elderly patients with ACS ( $\geq 65$ years old).

Methods: The study was conducted among 91 patients aged 65 years and over with ACS. The MacNew questionnaire was used to evaluate QoL and the Tilburg frailty indicator to evaluate frailty.

Results: FS was present in $82.4 \%$ of patients. The average Tilburg frailty indicator score was 7.43 \pm 2.57 . A negative correlation between the global values of FS and QoL was shown $(r=-0.549, P<0.05)$. The vulnerability factors that negatively affected early QoL were: FS, marital status, conservative therapy, and hypertension. In multivariate analysis, FS was found to be the independent predictor of worse QoL ( $\beta \pm$ standard error $-0.277 \pm 0.122, P=0.026$ ).

Conclusion: The presence of FS has a negative impact on early QoL in patients with ACS. The study suggests that in elderly patients with ACS, there is a need to identify frailty in order to implement additional therapeutic and nursing strategies in ACS.
\end{abstract}

Keywords: frailty syndrome, aging, frail elderly, assessment, quality of life, acute coronary syndrome

\section{Introduction}

Recently, the interest in geriatric condition evaluation has been increasing, especially with regard to frailty syndrome (FS) and its clinical significance in elderly cardiovascular patients. The increasing number of elderly patients necessitates more intensive diagnostic and therapeutic efforts and an enhancement of the patients' general quality of life (QoL). ${ }^{1}$ Cardiovascular conditions, including acute coronary syndrome (ACS), play a key role in determining $\mathrm{QoL}^{2}$ in terms of physical, emotional, and social functioning. Patients with a history of ACS constitute a diverse group, with various ACS types and various therapeutic strategies used. Medical evaluation does not incorporate the patients' subjective assessment of their condition or their QoL. Nowadays, the goal of treatment and of clinical studies on the consequences of cardiovascular conditions is not only reducing mortality, improving symptoms, and functional status but also increasing the patients' QoL. ${ }^{3}$ QoL studies allow a unique evaluation, taking into account each patient's individual needs and declared expectations, which can change during treatment due to "response shift". ${ }^{4}$ As regard to the FS, it has become a major concept in gerontology. It is considered an important clinical and social issue. ${ }^{5}$ Frailty has been associated with higher rates of cardiovascular disease (CVD). ${ }^{6}$
Correspondence: Izabella Uchmanowicz Department of Clinical Nursing, Wroclaw Medical University, Bartla 5 Street,

Wroclaw 51-616, Poland

Tel +48 7I 784 I824

Fax +48 7I 3459324

Email izabella.uchmanowicz@umed. wroc.pl
Clinical Interventions in Aging 2016:1 I 553-562

Dovepress

http://dx.doi.org/10.2147/CIA.S99842 (c) (i) (\$) 2016 Lisiak et al. This work is published and licensed by Dove Medical Press Limited. The full terms of this license are available at https://www.dovepress.com/terms.php cc) and incorporate the Creative Commons Attribution - Non Commercial (unported, v3.0) License (http://creativecommons.org/licenses/by-nc/3.0/). By accessing the work you hereby accept the Terms. Non-commercial uses of the work are permitted without any further permission from Dove Medical Press Limited, provided the work is properly attributed. For permission for commercial use of this work, please see paragraphs 4.2 and 5 of our Terms (https://www.dovepress.com/terms.php). 
Patients with FS are at a significantly higher risk of adverse outcomes such as disability, falls, hospitalization, institutionalization, and mortality. ${ }^{7-10}$ The pathomechanism of FS is a result of aging, and of various related physiological changes that may contribute to pathological processes, and consequently, to adverse outcomes. ${ }^{11}$ Nonetheless, there is no single scale or set of criteria for FS diagnosis. ${ }^{12-14}$ There are different diagnostic criteria and scales for frailty, with no consensus in literature as to the most appropriate factors for its identification. ${ }^{12}$ It is assumed that early diagnosis of the syndrome and a swift therapeutic intervention enhance QoL and decrease health care costs. ${ }^{9}$ Furthermore, frailty has significant implications for patients' independence and entails an increased risk of hospitalization, disability, institutionalization, and death. ${ }^{15}$

Literature includes papers describing the adverse influence of FS on QoL in community-housed elderly patients, depending on their health. ${ }^{16-30}$ However, the authors are not aware of any published analysis of the adverse influence of frailty on QoL in patients with ACS.

\section{Methods}

\section{Aim}

The aim of the study was to investigate the relationship between FS and QoL during hospitalization in elderly patients with ACS.

\section{Participants}

The study was conducted between June 2013 and April 2014 in elderly patients hospitalized for ACS. Inclusion criteria were: signing an informed consent form, age $\geq 65$ years, and ACS diagnosed according to the European Society of Cardiology guidelines. ${ }^{31,32}$ Exclusion criteria were: in-hospital complications (cardiogenic shock, sudden cardiac arrest, pulmonary edema), and cognitive deficiencies and/or barriers to communication preventing patient history taking and questionnaire completion. In order to evaluate any cognitive deficiencies, we used the Mini-Mental State Examination for assessing cognitive function. The patients were divided into three age groups (A, 65-75 years; B, 76-85 years; and C, 86-92 years). In the study, QoL evaluation was performed during hospitalization, prior to discharge. The study was based on the analysis of patients' questionnaires and data from records maintained by a cardiac nurse. QoL parameters were studied using the Polish version of the MacNew Heart Disease Health-related Quality of Life (MacNew) questionnaire. ${ }^{33}$ FS was evaluated using the Polish version of the Tilburg frailty indicator (TFI). ${ }^{34}$

\section{Ethical considerations}

The study protocol was approved by the Bioethics Committee of Wroclaw Medical University. The investigation conforms with the principles outlined in the Declaration of Helsinki (64th WMA General Assembly, Fortaleza, Brazil, October 2013). ${ }^{35}$

\section{Instruments}

The study used the Polish version of the MacNew questionnaire, which is a specific tool for health-related QoL evaluation in patients with cardiovascular conditions, including myocardial infarction. ${ }^{36}$ The scale comprises 27 questions pertaining to three domains of QoL: physical, psychological, and social, as well as to global QoL. Patients respond using a seven-point Likert scale. Higher scores indicate a higher QoL. The score is an arithmetic mean for each domain (for the number of questions answered in a given interview). A global QoL score can also be calculated. The MacNew questionnaire has been tested for reliability and validity in several European states, including Poland, since 2003. ${ }^{37}$ Höfer et $\mathrm{al}^{36}$ demonstrated the reliability and validity in the Dutch, English, Farsi, German, and Spanish versions of the MacNew. The internal consistency ranged from 0.75 to 0.97 , intraclass correlation coefficients were $\geq 0.73$, and reliability was high. The MacNew is responsive and sensitive to changes in health-related QoL following various interventions for patients with heart disease with eleven out of 13 effect size statistics $>0.80$. The MacNew is reliable and meets the reproducibility standard of 0.70 for group comparison, which usually is the goal in clinical trials. ${ }^{36}$

Although initially FS was mainly a medical concept, it is now regarded as a multidimensional issue affecting the patients' biopsychosocial nature, similarly to QoL. FS is described as a dynamic state comprising physical, psychological, and social determinants that may deteriorate over time, or improve - following proper diagnosis and treatment. ${ }^{13}$ Frailty was assessed using the Polish version of the TFI. ${ }^{34}$ TFI is a tool used for FS assessment, developed by Gobbens et al. ${ }^{38}$ The tool comprises of two parts: A (sociodemographic factors) and B (frailty components, 15 questions). Part B is divided into three domains: physical (eight questions), psychological (four questions), and social (three questions). Eleven questions in part B allow two answer options ("yes" and "no"), the remaining ones allow three ("yes," "no", and "sometimes"). The total TFI score is between 0 and 15 points. FS is diagnosed at TFI scores $\geq 5$ points. Uchmanowicz et al ${ }^{34}$ demonstrated that TFI was characterized by good construct validity, reliability, 
and acceptable internal consistency for Polish populations, with a mean total TFI score of $6.7 \pm 3.1$. Cronbach's alpha reliability coefficients of TFI ranged from 0.68 to 0.72 . This survey showed results similar to the original study performed by Gobbens et a ${ }^{39}$ (Dutch version of the TFI [0.79]) and to the Brazilian adaptation $(0.78){ }^{40}$

\section{Statistical analysis}

Statistical analysis of questionnaire data was performed using the STATISTICA 10 software (StatSoft Inc., Tulsa, OK, United States, 2011). ${ }^{41}$ The analysis investigated the influence of FS, as well as of selected sociodemographic and clinical factors, on early QoL measured using the MacNew questionnaire. Nominal data correlations were verified using Pearson's chi-squared test or Fisher's exact test. Correlations and differences at $P<0.05$ were considered statistically significant. Quantitative (measurable) data were presented as mean (M) with standard deviation (SD), as well as median (Me) and extreme (Min and Max) values. Empirical distribution normality was verified using the Shapiro-Wilk test. The significance of quantitative parameter differences between two groups of patients (male and female) was evaluated using Student's $t$-test (for variable distributions close to normal) or the Mann-Whitney $U$-test (for variables with distributions significantly different from normal). For comparisons concerning more than two groups (age, ACS type, treatment, etc), the Kruskal-Wallis test was used. To evaluate measurable data correlation strengths, Spearman's rank correlation coefficients were calculated $\left(r_{\mathrm{S}}\right)$. In the statistical analysis, we used the receiver operating characteristic plot, which provides a visual representation of the accuracy of a detection test, incorporating not only the intrinsic features of the test, but also variability of the reader. It allowed us to determine the optimal cutoff point. In addition, a multivariate analysis was performed, which included the variables that negatively affected QoL in the single-factor analysis.

\section{Results}

\section{Patient characteristics}

The study included 91 patients, 44 (48.4\%) female and 47 $(51.6 \%)$ male. The mean patient age was $76.7 \pm 7.8$ years. The largest age group was group B: $76-85$ years $(n=40,44.0 \%)$. Significantly, more men than women were married $(72.3 \%$ vs $27.3 \%, P<0.001)$, likely due to the fact that women were older than men, and that, on average, women have longer life spans. The numbers of married and single patients were comparable ( $50.6 \%$ vs $49.4 \%$, respectively), but it was noted that elderly patients were more likely to be single.
This relationship was noticed among three groups of patients ( $35.1 \%$ vs $50.0 \%$ vs $85.7 \%$, respectively). Most patients reported high school education (39.5\%), whereas the lowest percentage of patients (8.8\%) graduated from university. The vast majority lived in an urban environment (83.5\%) with their families (71.4\%). The most frequent comorbidity was arterial hypertension $(n=74,81.3 \%)$. Among the patients studied, $45 \%$ had ST elevation myocardial infarction, $45 \%$ had no ST elevation myocardial infarction, and 10\% had unstable angina. The most common treatment was percutaneous coronary intervention (PCI, 72.5\%), next conservative therapy (CT, 17.6\%), and coronary artery bypass graft (9.9\%). A total of $82.4 \%$ of the elderly patients with ACS were diagnosed with FS. The sociodemographic and clinical data of the 91 patients are shown in Table 1.

\section{Comparison of health-related QoL values in each MacNew domain: by age}

Multiple comparisons showed a statistical correlation between group A (65-75 years) and group B ( $76-85$ years) ( $4.7 \pm 0.7$ vs $4.2 \pm 0.9, P=0.043)$. In the physical and social domain, patients aged 65-75 years declared higher QoL than those aged $76-85$ years $(4.1 \pm 0.8$ vs $3.5 \pm 0.9, P=0.008$; and $5.1 \pm 0.7$ vs $4.4 \pm 0.9, P=0.009$, respectively). Other comparisons ( $\mathrm{A}$ vs $\mathrm{C}$ and $\mathrm{B}$ vs $\mathrm{C}$ ) did not show significant differences $(P>0.05)$. The results are shown in Table 2 .

\section{TFI domain values: by age}

The mean TFI score in the studied population was $7.43 \pm 2.57$ (Me 8 [5:9], range: 1-13). Post hoc analysis showed significant differences in TFI evaluation of FS in the global and physical domains between group A (65-75 years) and groups B and C (76-85 and 86-92 years). TFI scores in all domains increased with age, although statistically significant differences were only shown in the global and physical domains, between $\mathrm{A}$ and $\mathrm{B}$, and between $\mathrm{A}$ and $\mathrm{C}$. No significant differences between $\mathrm{B}$ and $\mathrm{C}$ were shown (Table 3).

\section{Correlations between global QoL and FS}

TFI scores and QoL were shown to be negatively correlated $(r=-0.549)$. Higher TFI scores were related to a lower global QoL evaluation in the MacNew questionnaire (Figure 1). The analysis of correlations between each TFI domain and each MacNew domain proved that all TFI domains are negatively correlated with MacNew domains, that is, higher TFI scores mean lower QoL of patients with ACS. The only exception was the social domain of TFI, which was negatively correlated only with the emotional domain of MacNew 
Table I Patients' sociodemographic and clinical characteristics

\begin{tabular}{|c|c|c|c|c|c|}
\hline \multirow{3}{*}{$\begin{array}{l}\text { Variable } \\
\text { n (\%) }\end{array}$} & \multirow{3}{*}{$\begin{array}{l}\text { All participants } \\
n=9 \text { I }\end{array}$} & \multicolumn{3}{|c|}{ Age (years) } & \multirow{3}{*}{$\begin{array}{l}\text { Test } \\
\text { result }\end{array}$} \\
\hline & & $65-75$ & $76-85$ & $86-92$ & \\
\hline & & $n=37$ & $n=40$ & $n=14$ & \\
\hline \multicolumn{6}{|l|}{ Sociodemographic } \\
\hline Age, $M \pm S D$ & $76.7 \pm 7.8$ & $68.9 \pm 3.9$ & $79.9 \pm 3.6$ & $87.9 \pm 2.1$ & $\mathbf{P}<0.00 \mathrm{I}^{\mathrm{a}}$ \\
\hline \multicolumn{6}{|l|}{ Sex } \\
\hline Female & $44(48.4 \%)$ & $10(27.0 \%)$ & $25(62.5 \%)$ & 9 (64.3\%) & \\
\hline Male & 47 (51.6\%) & 27 (73.0\%) & 15 (37.5\%) & 5 (35.7\%) & $P=0.003^{b}$ \\
\hline \multicolumn{6}{|l|}{ Marital status } \\
\hline Married & $46(50.6 \%)$ & 24 (64.9\%) & $20(50.0 \%)$ & $2(14.3 \%)$ & \\
\hline Single & 45 (49.4\%) & $13(35.1 \%)$ & $20(50.0 \%)$ & $12(85.7 \%)$ & $P=0.006^{b}$ \\
\hline \multicolumn{6}{|l|}{ Education } \\
\hline Primary & $21(23.1 \%)$ & $5(13.5 \%)$ & $10(25.0 \%)$ & $6(42.9 \%)$ & \\
\hline Vocational & $26(28.6 \%)$ & $13(35.1 \%)$ & II (27.5\%) & $2(14.3 \%)$ & \\
\hline High school & $36(39.5 \%)$ & 15 (40.5\%) & $16(40.0 \%)$ & 5 (35.7\%) & $P=0.442^{b}$ \\
\hline University & $8(8.8 \%)$ & $4(10.8 \%)$ & $3(7.5 \%)$ & I (7.I\%) & \\
\hline \multicolumn{6}{|l|}{ Residence } \\
\hline Urban & $76(83.5 \%)$ & 31 (83.8\%) & $34(85.0 \%)$ & II (78.6\%) & \\
\hline Rural & 15 (16.5\%) & $6(16.2 \%)$ & $6(15.0 \%)$ & $3(21.4 \%)$ & $P=0.854^{b}$ \\
\hline \multicolumn{6}{|l|}{ Living } \\
\hline With family & 65 (7I.4\%) & 27 (73.0\%) & 29 (72.5\%) & 9 (64.3\%) & \\
\hline Alone & $26(28.6 \%)$ & $10(27.0 \%)$ & II (27.5\%) & 5 (35.7\%) & $P=0.812^{b}$ \\
\hline \multicolumn{6}{|l|}{ Clinical } \\
\hline \multicolumn{6}{|l|}{ ACS type } \\
\hline STEMI & $4 \mathrm{I}(45.0 \%)$ & 18 (48.7\%) & I8 (45.0\%) & 5 (35.7\%) & \\
\hline NSTEMI & $4 \mathrm{I}(45.0 \%)$ & 15 (40.5\%) & 18 (45.0\%) & 8 (57.2\%) & $P=0.888^{b}$ \\
\hline UA & $9(10.0 \%)$ & $4(10.8 \%)$ & $4(10.0 \%)$ & I (7.I\%) & \\
\hline \multicolumn{6}{|l|}{ Treatment } \\
\hline $\mathrm{PCl}$ & 66 (72.5\%) & 32 (86.5\%) & $28(70.0 \%)$ & $6(42.8 \%)$ & \\
\hline $\mathrm{CT}$ & $16(17.6 \%)$ & $2(5.4 \%)$ & $10(25.0 \%)$ & $4(28.6 \%)$ & $P=0.007^{b}$ \\
\hline CABG & $9(9.9 \%)$ & $3(8.1 \%)$ & $2(5.0 \%)$ & $4(28.6 \%)$ & \\
\hline \multicolumn{6}{|l|}{ Comorbidities } \\
\hline Diabetes mellitus & $20(22.0 \%)$ & $6(16.2 \%)$ & II (27.5\%) & $3(21.4 \%)$ & $P=0.489^{b}$ \\
\hline Arterial hypertension & 74 (8I.2\%) & $26(70.3 \%)$ & $36(90.0 \%)$ & $12(85.7 \%)$ & $P=0.077^{b}$ \\
\hline History of CVA & 10 (11.0\%) & $4(10.8 \%)$ & $6(15.0 \%)$ & $0(0.0 \%)$ & $P=0.303^{b}$ \\
\hline COPD & 12 (I3.2\%) & $5(13.5 \%)$ & $7(17.5 \%)$ & $0(0.0 \%)$ & $P=0.249^{b}$ \\
\hline
\end{tabular}

Notes: aStudent's t-test, 'Pearson's chi-square test. Data in bold indicates statistical significance.

Abbreviations: (\%), interest; ACS, acute coronary syndrome; CABG, coronary artery bypass graft; COPD, chronic obstructive pulmonary disease; CT, conservative therapy; CVA, cerebrovascular accident; M, mean; n, cardinality; NSTEMI, no ST elevation myocardial infarction; PCl, percutaneous coronary intervention; SD, standard deviation; STEMI, ST elevation myocardial infarction; UA, unstable angina.

$\left(r_{\mathrm{S}}=-0.314, P<0.05\right)$, with no other correlations. The results are shown in Table 4.

Sociodemographic and clinical factors that may affect QoL independently of FS were also analyzed (Table 5). Overall QoL was higher among married patients. A positive trend in QoL during the time of hospitalization was observed in patients treated with PCI, compared to those undergoing CT $(P=0.043<0.05)$. Analysis of the influence of comorbidities on global MacNew QoL scores showed that only arterial hypertension negatively affected QoL during the time of hospitalization $(4.34 \pm 0.83$ vs $4.83 \pm 0.73, P=0.038)$. The results are shown in Table 5.
The results of the multiple regression analysis (using the forward stepwise method), which included the variables that negatively affected QoL in the single-factor analysis, are shown in Table 6. FS was shown to be an independent predictor of QoL.

To determine the cutoff value in each FS component (TFI domain), a global MacNew QoL score of $>4.5$ points was used as a criterion for good QoL (Figure 2).

\section{Discussion}

Two validated research instruments were used for this purpose: the MacNew questionnaire and the TFI. 
Table 2 QoL evaluation using the MacNew questionnaire in each domain: global, physical, emotional, and social

\begin{tabular}{|c|c|c|c|c|c|}
\hline \multirow{3}{*}{$\begin{array}{l}\text { QoL domains } \\
\text { (MacNew) (patients) }\end{array}$} & \multirow{3}{*}{$\begin{array}{l}\text { Total } \\
\mathbf{N}=91\end{array}$} & \multicolumn{3}{|l|}{ Age (years) } & \multirow[t]{3}{*}{ Comparison result ${ }^{a}$} \\
\hline & & $\bar{A}$ & B & C & \\
\hline & & $65-75$ & $76-85$ & $86-92$ & \\
\hline \multicolumn{6}{|l|}{ Global } \\
\hline$M \pm S D$ & $4.4 \pm 0.8$ & $4.7 \pm 0.7$ & $4.2 \pm 0.9$ & $4.4 \pm 0.6$ & \\
\hline $\operatorname{Me}\left(Q_{1} ; Q_{3}\right)$ & $4.5(3.8 ; 5.0)$ & $4.7(4.3 ; 5.2)$ & $4.3(3.4 ; 4.8)$ & $4.3(3.9 ; 4.8)$ & A vs $B$ \\
\hline Min-Max & $2.2-6.0$ & $4.3-6.0$ & $2.2-5.8$ & $3.3-5.6$ & $P=0.043$ \\
\hline \multicolumn{6}{|l|}{ Physical } \\
\hline$M \pm S D$ & $3.8 \pm 0.9$ & $4.1 \pm 0.8$ & $3.5 \pm 0.9$ & $3.7 \pm 0.6$ & \\
\hline $\operatorname{Me}\left(Q_{1} ; Q_{3}\right)$ & $3.8(3.2 ; 4.4)$ & $4.2(3.5 ; 4.6)$ & $3.5(2.8 ; 4.2)$ & $3.7(3.2 ; 4.2)$ & A vs $B$ \\
\hline Min-Max & $1.4-5.9$ & $2.8-5.9$ & $1.4-5.3$ & $2.6-4.8$ & $P=0.008$ \\
\hline \multicolumn{6}{|l|}{ Emotional } \\
\hline$M \pm S D$ & $4.8 \pm 1.0$ & $4.9 \pm 0.9$ & $4.6 \pm 1.2$ & $4.7 \pm 0.8$ & \\
\hline $\operatorname{Me}\left(Q_{1} ; Q_{3}\right)$ & $4.9(4.0 ; 5.5)$ & $4.9(4.3 ; 5.6)$ & $5.0(3.5 ; 5.5)$ & $4.9(3.9 ; 5.2)$ & A vs $B$ \\
\hline Min-Max & $2.2-6.9$ & $2.9-6.9$ & $2.2-6.9$ & $3.6-6.4$ & $P=0.655$ \\
\hline \multicolumn{6}{|l|}{ Social } \\
\hline$M \pm S D$ & $4.7 \pm 0.9$ & $5.1 \pm 0.7$ & $4.4 \pm 0.9$ & $4.7 \pm 0.6$ & \\
\hline $\operatorname{Me}\left(Q_{1} ; Q_{3}\right)$ & $4.8(4.1 ; 5.4)$ & $5.2(4.5 ; 5.5)$ & $4.4(3.6 ; 5.2)$ & $4.7(4.2 ; 5.2)$ & A vs $B$ \\
\hline Min-Max & $2.5-6.6$ & $3.2-6.6$ & $2.5-6.2$ & $3.5-5.6$ & $P=0.009$ \\
\hline
\end{tabular}

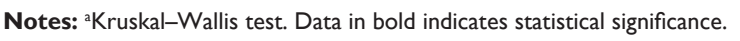

Abbreviations: M, mean; Max, the value of the largest; Me, median; Min, the smallest value; $Q_{1}$, lower quartile (25th percentile); $Q_{3}$, the upper quartile (75th percentile); QoL, quality of life; SD, standard deviation.

Cardiovascular conditions, including ACS, are among the most common causes of death for elderly patients worldwide. With the ongoing development in medical science, improving the QoL of these patients becomes another achievable goal, aside from prolonging their lives. ${ }^{42}$ Functional deficits in elderly patients, including all biopsychosocial limitations, are due, among other factors, to FS. ${ }^{43}$ This is why special focus is placed on identifying FS and applying early treatment, especially in cardiovascular patients. The American Heart Association and the Society of Geriatric Cardiology recognize the need for FS assessment in elderly patients with ACS. ${ }^{44}$ Some studies document an association between FS and CVD. ${ }^{45-49}$ It is known that they share a common biological and epidemiological pathway. Additionally, CVD

Table 3 FS evaluation in each domain: global, physical, psychological, and social

\begin{tabular}{|c|c|c|c|c|c|}
\hline \multirow{3}{*}{$\begin{array}{l}\text { Tilburg scale scores } \\
\text { (patients) }\end{array}$} & \multirow{3}{*}{$\begin{array}{l}\text { Total } \\
\mathbf{N}=9 \text { I }\end{array}$} & \multicolumn{3}{|c|}{ Age (years) } & \multirow[t]{3}{*}{ Comparison result ${ }^{a}$} \\
\hline & & $65-75$ & $76-85$ & $86-92$ & \\
\hline & & $\mathbf{N}=\mathbf{3 7}$ & $\mathbf{N}=\mathbf{4 0}$ & $N=14$ & \\
\hline \multicolumn{6}{|l|}{ Global } \\
\hline$M \pm S D$ & $7.43 \pm 2.57$ & $5.70 \pm 2.22$ & $8.42 \pm 2.18$ & $9.14 \pm 1.79$ & \\
\hline $\operatorname{Me}\left(Q_{1} ; Q_{3}\right)$ & $8(5 ; 9)$ & $5(4 ; 8)$ & $8(7 ; 10)$ & $9(8 ; 10)$ & $\mathbf{P}<\mathbf{0 . 0 0 1}$ \\
\hline Min-Max & $1-13$ & $|-| I$ & $4-13$ & $5-12$ & \\
\hline \multicolumn{6}{|l|}{ Physical } \\
\hline$M \pm S D$ & $5.04 \pm 1.88$ & $3.49 \pm 1.63$ & $6.05 \pm 1.18$ & $6.29 \pm 1.14$ & \\
\hline $\operatorname{Me}\left(Q_{1} ; Q_{3}\right)$ & $5(4 ; 6)$ & $3(2 ; 5)$ & $6(5 ; 7)$ & $6(6 ; 7)$ & $\mathbf{P}<\mathbf{0 . 0 0 I}$ \\
\hline Min-Max & $0-8$ & $0-7$ & $4-8$ & $4-8$ & \\
\hline \multicolumn{6}{|l|}{ Psychological } \\
\hline$M \pm S D$ & $1.53 \pm 0.96$ & $1.32 \pm 0.91$ & $1.62 \pm 0.98$ & $1.79 \pm 0.97$ & \\
\hline $\operatorname{Me}\left(Q_{1} ; Q_{3}\right)$ & $2(I ; 2)$ & $I(I ; 2)$ & $2(I ; 2)$ & $2(I ; 2)$ & $P=0.159$ \\
\hline Min-Max & $0-3$ & $0-3$ & $0-3$ & $0-3$ & \\
\hline \multicolumn{6}{|l|}{ Social } \\
\hline$M \pm S D$ & $0.88 \pm 0.74$ & $0.89 \pm 0.77$ & $0.82 \pm 0.7 \mid$ & $1.00 \pm 0.78$ & \\
\hline $\operatorname{Me}\left(Q_{1} ; Q_{3}\right)$ & I $(0 ; 1)$ & I $(0 ; 1)$ & I $(0 ; 1)$ & I $(0 ; 2)$ & $P=0.716$ \\
\hline Min-Max & $0-3$ & $0-3$ & $0-3$ & $0-2$ & \\
\hline
\end{tabular}

Notes: aKruskal-Wallis test. Data in bold indicates statistical significance.

Abbreviations: FS, frailty syndrome; M, mean; Max, the value of the largest; Me, median; Min, the smallest value; $Q_{1}$, lower quartile (25th percentile); $Q_{3}$, the upper quartile (75th percentile); SD, standard deviation. 


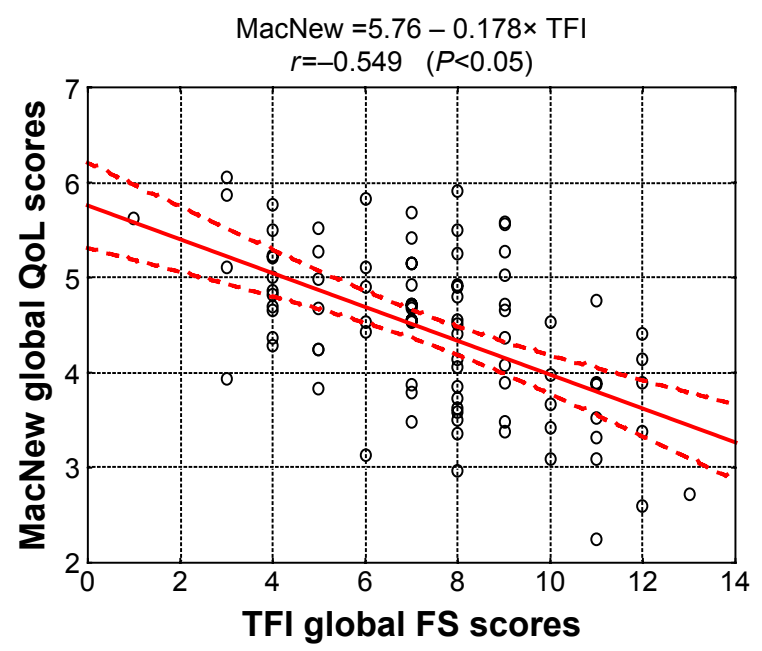

Figure I Diagram of correlations between MacNew global QoL scores and TFI global FS scores.

Abbreviations: FS, frailty syndrome; QoL, quality of life; FS, frailty syndrome; TFI, Tilburg frailty indicator.

may accelerate the development of frailty. ${ }^{6}$ In the present study, the prevalence of frailty measured using the TFI was $82.4 \%$. In other studies, the percentage is lower, between $25 \%$ and $50 \%,{ }^{50}$ and up to $74 \%$ for cardiovascular patients. ${ }^{6}$ Some explanations for such a high FS prevalence in the studied population might be poor initial health resulting from ACS, limitations in daily activities, and the use of invasive procedures. One should note that the percentage of FS diagnoses also depends on the research tool used..$^{10,12,19,43}$

Many studies on frailty have shown a strong correlation between FS and lower QoL, but there is a shortage of studies showing the influence of FS on QoL in elderly patients with ACS. Mansur et $\mathrm{al}^{17}$ and Sclauzero et a ${ }^{18}$ studied patients with chronic kidney disease. The Short Form-36 questionnaire was used, showing that seven out of eight domains were significantly different between frail and nonfrail patients with chronic kidney disease and there were correlations between

Table 4 Spearman's rank correlation coefficients $\left(r_{s}\right)$ for MacNew questionnaire domains and TFI domains

\begin{tabular}{lllll}
\hline $\begin{array}{l}\text { Tilburg } \\
\text { domains }\end{array}$ & \multicolumn{4}{l}{ MacNew questionnaire domains } \\
\cline { 2 - 5 } & Physical & Emotional & Social & Global \\
\hline Physical & $\boldsymbol{r}_{\mathrm{s}}=-\mathbf{0 . 3 7 2}$ & $\mathbf{r}_{\mathrm{s}}=-\mathbf{0 . 2 7 4}$ & $\boldsymbol{r}_{\mathrm{s}}=-\mathbf{0 . 3 6 7}$ & $\boldsymbol{r}_{\mathrm{s}}=-\mathbf{0 . 3 6 3}$ \\
& $\mathbf{P}<\mathbf{0 . 0 5}$ & $\mathbf{P}<\mathbf{0 . 0 5}$ & $\mathbf{P}<\mathbf{0 . 0 5}$ & $\mathbf{P}<\mathbf{0 . 0 5}$ \\
Psychological & $\boldsymbol{r}_{\mathrm{s}}=-\mathbf{0 . 3 7 9}$ & $\boldsymbol{r}_{\mathrm{s}}=-\mathbf{0 . 6 2 7}$ & $\boldsymbol{r}_{\mathrm{s}}=-\mathbf{0 . 3 7 7}$ & $\boldsymbol{r}_{\mathrm{s}}=-\mathbf{0 . 5 3 7}$ \\
& $\mathbf{P}<\mathbf{0 . 0 5}$ & $\mathbf{P}<\mathbf{0 . 0 5}$ & $\mathbf{P}<\mathbf{0 . 0 5}$ & $\mathbf{P}<\mathbf{0 . 0 5}$ \\
Social & $r_{\mathrm{s}}=-0.036$ & $\boldsymbol{r}_{\mathrm{s}}=-\mathbf{0 . 3 1 4}$ & $r_{\mathrm{s}}=+0.072$ & $r_{\mathrm{s}}=+0.129$ \\
& $\mathbf{P}>0.05$ & $\mathbf{P}<\mathbf{0 . 0 5}$ & $\mathbf{P}>0.05$ & $\mathbf{P}>0.05$ \\
Global & $\boldsymbol{r}_{\mathrm{s}}=-\mathbf{0 . 4 4 7}$ & $\mathbf{r}_{\mathrm{s}}=-\mathbf{0 . 5 1 5}$ & $\boldsymbol{r}_{\mathrm{s}}=-\mathbf{0 . 4 0 6}$ & $r_{\mathrm{s}}=-0.514$ \\
& $\mathbf{P}<\mathbf{0 . 0 5}$ & $\mathbf{P}<\mathbf{0 . 0 5}$ & $\mathbf{P}<\mathbf{0 . 0 5}$ & $\mathbf{P}<0.05$ \\
\hline
\end{tabular}

Note: Data in bold indicates statistical significance.

Abbreviation: TFI, Tilburg frailty indicator. frailty and QoL domains, excluding indices of social functioning. Additionally, components of frailty, such as dependence, malnutrition, disability, poor social and economic conditions had a significant effect on QoL. Bilotta et $\mathrm{a}^{23}$ proved that physical frailty status assessed by the Study of Osteoporotic Fractures criteria negatively affected five out of seven dimensions of QoL examined using the older people's QoL questionnaire in a sample of Italian older adults. Analogous findings were shown in studies of community-dwelling Chinese, ${ }^{26}$ Mexican American, ${ }^{21}$ North American, ${ }^{16}$ and Taiwanese older adults, ${ }^{19}$ where nonfrail subjects had a better QoL than frail subjects. In these studies, frailty was evaluated using the Fried criteria and QoL was evaluated using the Short Form-36 questionnaire. Gobbens et a ${ }^{28}$ in a study on a Dutch sample of older adults, where the TFI and the WHO quality of life-BREF questionnaire were used, demonstrated that frailty and QoL had strong correlations.

To the best of our knowledge, this is the first study to investigate the relationship between frailty and QoL during the time of hospitalization in elderly patients with ACS. Our study demonstrated that the presence of FS has an impact on QoL in patients with ACS. A negative correlation between TFI domains and MacNew domains in patients with ACS suggests a moderate relationship between FS and QOL. In the study population, it was observed that women were older compared to men. This situation undoubtedly affects the fact that older women often remain single. The study showed that QoL scores in patients with ACS become even lower with age. In addition, the FS evaluation showed that in the three treatment groups divided by age, there was a gradual increase in the TFI questionnaire score. Therefore, the understanding of FS's influence on QoL in elderly patients with ACS should provide guidance for applying new diagnostic and therapeutic interventions, especially that frailty is considered a significant predictor of adverse outcomes and poor QoL in elderly patients with CVD. The study showed that QoL improvement in patients with ACS was larger following the relief of angina with PCI treatment than following CT. Similarly to other authors' reports, ${ }^{51-55}$ patients treated with PCI had better outcomes, not only in terms of clinical variables (reduction in angina, survival advantage) but also better QoL. It should be stated, though, that data in this area is still limited, especially in the elderly population, but we believe that further studies will confirm the previous results, yielding patient-centered benefits.

Little is known about the relationship between frailty and the different aspects of QoL in general, and about any 
Table 5 Influence of demographic characteristics, clinical factors and comorbidities on global MacNew QoL scores

\begin{tabular}{|c|c|c|c|c|}
\hline \multirow[t]{2}{*}{ Variable } & \multicolumn{3}{|c|}{ MacNew: Global QoL } & \multirow[t]{2}{*}{ Comparison result } \\
\hline & $\mathbf{M} \pm \mathbf{S D}$ & $\operatorname{Me}\left(Q_{1} ; Q_{3}\right)$ & Min-Max & \\
\hline \multicolumn{5}{|l|}{ Marital status } \\
\hline Married & $4.62 \pm 0.81$ & $4.69(3.90 ; 5.25)$ & $2.97-6.05$ & $P=0.047^{a}$ \\
\hline Single & $4.25 \pm 0.82$ & $4.40(3.72 ; 4.80)$ & $2.25-5.88$ & \\
\hline \multicolumn{5}{|l|}{ Education } \\
\hline Primary & $4.29 \pm 0.89$ & $4.15(3.62 ; 5.00)$ & $2.72-6.05$ & $P=0.728^{b}$ \\
\hline Vocational & $4.39 \pm 0.78$ & $4.59(3.85 ; 5.52)$ & $2.25-5.52$ & \\
\hline High school & $4.5 I \pm 0.88$ & $4.61(3.85 ; 5.15)$ & $2.60-5.90$ & \\
\hline University & $4.63 \pm 0.69$ & $4.59(4.08 ; 5.09)$ & $3.72-5.78$ & \\
\hline \multicolumn{5}{|l|}{ Living } \\
\hline With family & $4.47 \pm 0.87$ & $4.25(3.82 ; 5.15)$ & $2.72-6.05$ & $P=0.654^{\mathrm{a}}$ \\
\hline Alone & $4.34 \pm 0.76$ & $4.59(3.90 ; 4.90)$ & $2.25-5.28$ & \\
\hline \multicolumn{5}{|l|}{ ACS type } \\
\hline STEMI & $4.48 \pm 0.82$ & $4.53(3.83 ; 5.15)$ & $2.60-5.83$ & \\
\hline NSTEMI & $4.45 \pm 0.84$ & $4.65(3.93 ; 4.98)$ & $2.25-6.05$ & STEMI vs NSTEMI \\
\hline UA & $4.19 \pm 0.88$ & $3.90(3.53 ; 4.68)$ & $3.13-5.68$ & $P=0.587$ \\
\hline \multicolumn{5}{|l|}{ Treatment } \\
\hline $\mathrm{PCl}$ & $4.56 \pm 0.82$ & $4.66(3.90 ; 5.15)$ & $2.25-6.05$ & \\
\hline CABG & $4.35 \pm 0.63$ & $4.55(4.05 ; 4.80)$ & $3.10-5.15$ & $\mathrm{PCl}$ vs CT \\
\hline CT & $3.96 \pm 0.85$ & $3.90(3.36 ; 4.49)$ & $2.60-5.68$ & $P=0.043$ \\
\hline \multicolumn{5}{|l|}{ Comorbidities } \\
\hline Diabetes mellitus & $4.6 I \pm 0.78$ & $4.73(3.95 ; 5.21)$ & $3.38-5.90$ & \\
\hline Arterial hypertension & $4.34 \pm 0.83$ & $4.4 I(3.80 ; 4.93)$ & $2.25-6.05$ & \\
\hline Hypercholesterolemia & $4.42 \pm 0.69$ & $4.55(3.89 ; 4.95)$ & $3.10-5.78$ & \\
\hline Renal insufficiency & $4.30 \pm 0.80$ & $4.16(3.83 ; 4.90)$ & $2.73-5.68$ & \\
\hline COPD & $4.22 \pm 1.22$ & $4.26(3.31 ; 5.30)$ & $2.25-5.88$ & \\
\hline History of CVA & $3.98 \pm 1.07$ & $3.99(2.98 ; 4.70)$ & $2.60-5.58$ & \\
\hline
\end{tabular}

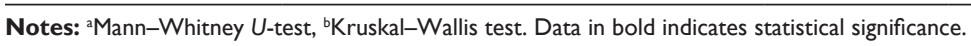

Abbreviations: ACS, acute coronary syndrome; CABG, coronary artery bypass graft; COPD, chronic obstructive pulmonary disease; CT, conservative therapy; CVA, cerebrovascular accident; M, Mean; Max, the value of the largest; Me, median; Min, the smallest value; NSTEMI, no ST elevation acute coronary syndrome; PCI, percutaneous coronary intervention; QI, lower quartile (25th percentile); Q3, the upper quartile (75th percentile); SD, standard deviation; STEMI, ST elevation myocardial infarction; UA, unstable angina.

interventions improving QoL in frail patients with ACS. We believe in the great importance of paying special attention to the specific needs of frail patients with ACS, in order to improve their functional and mental independence and their QoL.

\section{Study limitations}

The study has a few potential limitations. One such limitation is the fact that our sample was relatively small and was recruited at a single center. Additionally, the subjective evaluation of QoL can be adversely affected by the current hospitalization, poorer health, and other symptoms that significantly impair daily functioning. The study should be continued, with the same group of subjects, within 6 months after their ACS incident.

\section{Conclusion}

FS contributes to a decrease in the QoL of patients with ACS in all its four dimensions (physical, psychological, social, and global). Correlations have been shown between TFI

Table 6 QoL models

\begin{tabular}{lllll}
\hline Global score (QoL) & \multicolumn{2}{l}{ Simple regression } & & \multicolumn{2}{l}{ Stepwise multiple regression } \\
\cline { 2 - 4 } & $\boldsymbol{\beta} \pm \mathbf{S E}$ & $\mathbf{P}$-value & $< \pm \mathbf{S E}$ & $\mathbf{P}$-value \\
\hline FS & $-0.423 \pm 0.096$ & $<0.001$ & $-\mathbf{0 . 2 4 6} \pm \mathbf{0 . 1 2 2}$ & $>0.05$ \\
Single & $-0.223 \pm 0.103$ & $\mathbf{0 . 0 3 4}$ & - & $>0.05$ \\
Conservative therapy & $-0.263 \pm 0.102$ & $\mathbf{0 . 0 1 2}$ & - & $>0.05$ \\
Arterial hypertension & $-0.230 \pm 0.103$ & $\mathbf{0 . 0 2 8}$ & - & $\mathbf{0 . 0 2 6}$ \\
TFI $>$ 7 & $-0.434 \pm 0.095$ & $<\mathbf{0 . 0 0 1}$ & $-\mathbf{0 . 2 7 7} \pm \mathbf{0 . 1 2 2}$ & \\
\hline
\end{tabular}

Note: Data in bold indicates statistical significance.

Abbreviations: $\beta$, standardized beta coefficient for independent variables; FS, frailty syndrome; QoL, quality of life; SE, standard error; TFI, Tilburg frailty indicator; -, not applicable. 


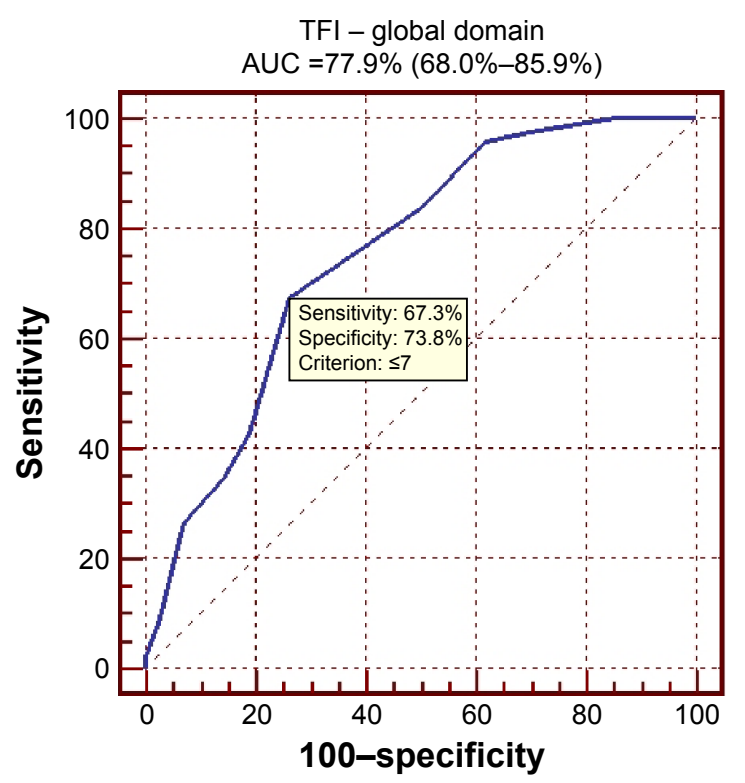

Figure 2 ROC curve for the global TFI score (cutoff value: $T F I \leq 7$ ). Abbreviations: ROC, receiver operating characteristic; TFI, Tilburg frailty indicator; AUC, area under ROC curve.

domains and QoL domains. Therefore, FS assessment is an important factor determining the patients' QoL. Identifying FS might become a factor contributing to a change in the therapeutic approach.

The study showed correlations between each QoL domain and the TFI domains of FS assessment, demonstrating the multidimensional nature of FS. Early FS diagnosis will enable the implementation of the appropriate efforts to improve the general QoL of elderly patients with ACS.

\section{Implications for practice}

The conducted study proved that identification of a frail person is important for clinical care and research. This is significant due to the fact that frailty is prevalent in older people and involves a progressive physiological decline in reserve and function across multiple physiologic systems. The complex care plan beyond the QoL assessment should take into account assessment of a frail person who requires additional intervention. It is worth mentioning that early identification of FS among elderly patients with ACS will enable the implementation of the appropriate diagnostic and therapeutic efforts to potentially prevent or delay the clinical consequence of frailty and improve the general QoL. Furthermore, the assessment of FS will allow an adjustment of nursing interventions provided to frail patients. Frail older adults potentially require an intervention which influence on improvement of QoL and biopsychosocial nature of person. It is confirmed that some sociodemographic factors, such as being married, having completed higher education, living with family, and some clinical factors like PCI, fewer comorbidities contribute to improved early QoL care in frail elderly. Care consideration of the frail should analyze not only the decision about appropriate treatment, but also needs to include the necessities of daily care, such as exercise including resistance and strength, supplementation of nutritious meals, environmental modification, transportation to health care appointments, medications, home maintenance and safety, and family and professional caregiver education. It is emphasized that nurses can assess frailty and initiate intervention to prevent functional dependence. Nowadays, nursing care services must develop in response to the needs of the frail adults and participate in changes of the health care system.

\section{Disclosure}

The authors report no conflicts of interest in this work.

\section{References}

1. Jackson CF, Wenger NK. Cardiovascular disease in the elderly. Rev Esp Cardiol. 2011;64(8):697-712.

2. Dias CC, Mateus P, Santos L, et al. Acute coronary syndrome and predictors of quality of life. Rev Port Cardiol. 2005;24(6):819-831.

3. Thompson DR, Yu CM. Quality of life in patients with coronary heart disease-I: assessment tools. Health Qual Life Outcomes. 2003;10(1):42.

4. Carr AJ, Gibson B, Robinson PG. Measuring quality of life: Is quality of life determined by expectations or experience? BMJ. 2001;322(7296):1240-1243.

5. Fisher AL. Just what defines frailty? J Am Geriatr Soc. 2005;53(12): 2229-2230.

6. Afilalo J, Karunananthan S, Eisenberg MJ, Alexander KP, Bergman H. Role of frailty in patients with cardiovascular disease. Am J Cardiol. 2009;103(11):1616-1621.

7. Chen CC, Yen CJ, Dai YT, Wang C, Huang GH. Prevalence of geriatric conditions: a hospital-wide survey of 455 geriatric inpatients in a tertiary medical center. Arch Gerontol Geriatr. 2011;53(1):46-50.

8. Mitnitski AB, Mogilner AJ, MacKnight C, Rockwood K. The mortality rate as a function of accumulated deficits in a frailty index. Mech Ageing Dev. 2002;123(11):1457-1460.

9. Morley JE, Vellas B, Van Kan GA, et al. Frailty consensus: a call to action. J Am Med Dir Assoc. 2013;14(6):392-397.

10. Fried LP, Tangen CM, Walston J, et al. Frailty in older adults: evidence for a phenotype. J Gerontol A Biol Sci Med Sci. 2001;56(3):146-156.

11. Clegg A, Young J, Iliffe S, Rikkert MO, Rockwood K. Frailty in elderly people. Lancet. 2013;381(9868):752-762.

12. Uchmanowicz I, Lisiak M, Jankowska-Polańska B. Research instrument used in the assessment of the frailty syndrome. Gerontol Pol. 2014;22(1):1-8.

13. Gobbens RJ, Luijkx KG, Wijnen-Sponselee MT, Schols JM. In search of an integral conceptual definition of frailty: opinions of experts. J Am Med Dir Assoc. 2010;11(5):338-343.

14. Markle-Reid M, Browne G. Conceptualizations of frailty in relation to older adults. $J$ Adv Nurs. 2003;44(1):58-68. 
15. Heuberger RA. The frailty syndrome: a comprehensive review. J Nutr Gerontol Geriatr. 2011;30(4):315-368.

16. Kanwar A, Singh M, Lennon R, Ghanta K, McNallan SM, Roger VL. Frailty and health-related quality of life among residents of long-term care facilities. J Aging Health. 2013;25(5):792-802.

17. Mansur HN, Colugnati FA, Grincenkov FR, Bastos MG. Frailty and quality of life: a cross-sectional study of Brazilian patients with pre-dialysis chronic kidney disease. Health Qual Life Outcomes. 2014; 12:27.

18. Sclauzero P, Galli G, Barbati G, Carraro M, Panzetta GO. Role of components of frailty on quality of life in dialysis patients: a crosssectional study. J Ren Care. 2013;39(2):96-102.

19. Lin CC, Li CI, Chang CK, et al. Reduced health-related quality of life in elders with frailty: a cross-sectional study of community-dwelling elders in Taiwan. PLoS One. 2011;6(7):e21841.

20. Masel MC, Ostir GV, Ottenbacher KJ. Frailty, mortality, and health related quality of life in older Mexican Americans. J Am Geriatr Soc. 2010;58(11):2149-2153

21. Masel MC, Graham JE, Reistetter TA, Markides KS, Ottenbacher KJ. Frailty and health related quality of life in older Mexican Americans. Health Qual Life Outcomes. 2009;7:70.

22. Kanauchi M, Kubo A, Kanauchi K, Saito Y. Frailty, health-related quality of life and mental well-being in older adults with cardiometabolic risk factors. Int J Clin Pract. 2008;62(9):1447-1451.

23. Bilotta C, Bowling A, Casè A, et al. Dimensions and correlates of quality of life according to frailty status: a cross-sectional study on community-dwelling older adults referred to an outpatient geriatric service in Italy. Health Qual Life Outcomes. 2010;8(8):56.

24. Bautmans I, Njemini R, Predom H, Lemper JC, Mets J. Muscle endurance in elderly nursing home residents is related to fatigue perception, mobility, and circulating tumor necrosis factor-alpha, interleukin-6, and heat shock protein 70. J Am Geriatr Soc. 2008;56(3): 389-396.

25. Puts MT, Shekary N, Widdershoven G, Heldens J, Lips P, Deeg DJ. What does quality of life mean to older frail and non-frail community-dwelling adults in the Netherlands? Qual Life Res. 2007;16(2): 263-277.

26. Chang YW, Chen WL, Lin FG, et al. Frailty and its impact on health-related quality of life: a cross-sectional study on elder community-dwelling preventive health service users. PLoS One. 2012;7(5):e38079.

27. Gobbens RJ, Luijkx KG, Van Assen MA. Explaining quality of life of older people in the Netherlands using a multidimensional assessment of frailty. Qual Life Res. 2013;22(8):2051-2061.

28. Gobbens RJ, Van Assen MA. The prediction of quality of life by physical, psychological and social components of frailty in communitydwelling older people. Qual Life Res. 2014;23(8):2289-2300.

29. Mulasso A, Roppolo M, Rabaglietti E. The role of individual characteristics and physical frailty on health related quality of life (HRQOL): A cross sectional study of Italian community-dwelling older adults. Arch Gerontol Geriatr. 2014;59(3):542-548.

30. Mhaoláin AM, Gallagher D, Crosby L, et al. Frailty and quality of life for people with Alzheimer's dementia and mild cognitive impairment. Am J Alzheimers Dis Other Demen. 2012;27(1):48-54.

31. Steg PG, James SK, Atar D, et al. Task Force on the management of ST-segment elevation acute myocardial infarction of the European Society of Cardiology. ESC Guidelines for the management of acute myocardial infarction in patients presenting with ST-segment elevation. Eur Heart J. 2012;33(20):2569-2619.

32. Hamm CW, Bassand JP, Agewall S, et al. ESC Guidelines for the management of acute coronary syndromes in patients presenting without persistent ST-segment elevation: The Task Force for the management of acute coronary syndromes (ACS) in patients presenting without persistent ST-segment elevation of the European Society of Cardiology (ESC). Eur Heart J. 2011;32(23):2999-3054.

33. Wrześniewski K. How to assess quality of life of cardiological patients? Kardiol Pol. 2009;67:790-794.
34. Uchmanowicz I, Jankowska-Polańska B, Łoboz-Rudnicka M, Manulik S, Łoboz-Grudzień K, Gobbens RJ. Cross-cultural adaptation and reliability testing of the Tilburg Frailty Indicator for optimizing care of Polish patients with frailty syndrome. Clin Interv Aging. 2014;9:997-1001.

35. World Medical Association. World Medical Association Declaration of Helsinki: ethical principles for medical research involving human subjects. JAMA. 2013;310:2191-2194.

36. Höfer S, Lim L, Guyatt G, Oldrige N. The MacNew heart disease health-related quality of life instrument: a summary. Health Qual Life Outcome. 2004;2:3.

37. Broda G. [Quality of life - an important measure of health]. Jakość życiaważny pomiar zdrowia. Kardiol Pol. 2009;67:10. Polish.

38. Gobbens RJ, Van Assen MA, Luijkx KG, Schols JM. The predictive validity of the Tilburg Frailty Indicator: disability, health care utilization, and quality of life in a population at risk. Gerontologist. 2012;52(5): 619-631.

39. Gobbens RJ, van Assen MA, Luijkx KG, Wijnen-Sponselee MT, Schols J. The Tilburg Frailty Indicator: psychometric properties. $J$ Am Med Dir Assoc. 2010;11(5):344-355.

40. Santiago LM, Luz LL, Mattos IE, Gobbens RJ, van Assen MA. Psychometric properties of the Brazilian version of the Tilburg frailty indicator (TFI). Arch Gerontol Geriatr. 2013;57(1):39-45.

41. StatSoft Inc. STATISTICA (data analysis software system), version 10; 2011. Available from: www.statsoft.com. Accessed November 30, 2014.

42. Veerasamy M, Edwards R, Fors G, et al. Acute coronary syndrome among older patients: a review. Cardiol Rev. 2015;23(1):26-32.

43. Afilalo J. Frailty in patients with cardiovascular disease: why, when, and how to measure. Curr Cardiovasc Risk Rep. 2011;5(5):467-472.

44. Alexander KP, Newby LK, Cannon CP, et al. Acute coronary care in the elderly, part I: Non-ST-segment-elevation acute coronary syndromes: a scientific statement for healthcare professionals from the American Heart Association Council on Clinical Cardiology: in collaboration with the Society of Geriatric Cardiology. Circulation. 2007; 115(19):2549-2569.

45. Newman AB, Gottdiener JS, Mcburnie MA, et al. Associations of subclinical cardiovascular disease with frailty. J Gerontol A Biol Sci Med Sci. 2001;56(3):M158-M166.

46. Chaves PH, Semba RD, Leng SX, et al. Impact of anemia and cardiovascular disease on frailty status of community-dwelling older women: the Women's Health and Aging Studies I and II. J Gerontol A Biol Sci Med Sci. 2005;60(6):729-735.

47. Newman AB, Simonsick EM, Naydeck BL, et al. Association of long-distance corridor walk performance with mortality, cardiovascular disease, mobility limitation, and disability. JAMA. 2006; 295(17):2018-2026.

48. Purser JL, Kuchibhatla MN, Fillenbaum GG, Harding T, Peterson ED, Alexander KP. Identifying frailty in hospitalized older adults with significant coronary artery disease. $J$ Am Geriatr Soc. 2006;54(11): 1674-1681.

49. Cacciatore F, Abete P, Mazzella F, et al. Frailty predicts long-term mortality in elderly subjects with chronic heart failure. Eur J Clin Invest. 2005;35(12):723-730.

50. Song X, Mitnitski A, Rockwood K. Prevalence and 10-year outcomes of frailty in older adults in relation to deficit accumulation. $J$ Am Geriatr Soc. 2010;58(4):681-687.

51. Boden WE, O'Rourke RA, Teo KK, et al. Optimal medical therapy with or without PCI for stable coronary disease. $N$ Engl J Med. 2007; 356(15):1503-1516.

52. Spertus JA, Salisbury AC, Jones PG, Conaway DG, Thompson RC. Predictors of quality-of-life benefit after percutaneous coronary intervention. Circulation. 2004;110(25):3789-3794.

53. Boersma E; Primary Coronary Angioplasty vs Thrombolysis Group. Does time matter? A pooled analysis of randomized clinical trials comparing primary percutaneous coronary intervention and in-hospital fibrinolysis in acute myocardial infarction patients. Eur Heart J. 2006;27(7):779-788. 
54. Stenestrand U, Lindback J, Wallentin L; RIKS-HIA Registry. Long-term outcome of primary percutaneous coronary intervention vs prehospital and in-hospital thrombolysis for patients with ST-elevation myocardial infarction. JAMA. 2006;296(14):1749-1756.
55. Bavry AA, Kumbhani DJ, Rassi AN, Bhatt DL, Askari AT. Benefit of early invasive therapy in acute coronary syndromes: a meta-analysis of contemporary randomized clinical trials. J Am Coll Cardiol. 2006; 48(7):1319-1325.

\section{Publish your work in this journal}

Clinical Interventions in Aging is an international, peer-reviewed journal focusing on evidence-based reports on the value or lack thereof of treatments intended to prevent or delay the onset of maladaptive correlates of aging in human beings. This journal is indexed on PubMed Central, MedLine,
CAS, Scopus and the Elsevier Bibliographic databases. The manuscript management system is completely online and includes a very quick and fair peer-review system, which is all easy to use. Visit http://www.dovepress. com/testimonials.php to read real quotes from published authors. 